\title{
Characteristic of Noise-induced Hearing Loss among Workers in Construction Industries
}

\author{
Ain Naadia Mazlan ${ }^{1}$, Khairulzan Yahya ${ }^{1}$, Zaiton Haron ${ }^{1, *}$, Nik Amsharija Mohamed ${ }^{2}$, \\ Edrin Nazri Abdul Rasib ${ }^{2}$, Nizam Jamaludin ${ }^{2}$, and Nadirah Darus ${ }^{1}$ \\ ${ }^{1}$ Faculty of Civil Engineering, Universiti Teknologi Malaysia, 81310 Johor Bahru, Johor, Malaysia \\ ${ }^{2}$ Social Security Organisation, Menara PERKESO, No. 281, Jalan Ampang,50538 Kuala Lumpur
}

\begin{abstract}
Noise-induced hearing loss (NIHL) is among the most common occupational disease in industries. This paper investigates NIHL in construction related industries in Malaysia with particular emphasis on its relation with risk factors. The objectives of this research were to (1) quantify the prevalence of NIHL in construction related industries, and (2) assess the relationship between hearing loss and risk factors and it's characteristic. The study was conducted using 110 NIHL compensation record collected from Social Security Organisation (SOCSO), Malaysia. Risk factors namely area noise, age, temperature, smoking habit, hobby, diabetic and cardiovascular disease were identified and analysed. Results showed that there was no direct relationship between area noise with hearing impairment while there was only low relationship between age and hearing impairment. The range for area noise and age were between 70 to $140 \mathrm{~dB}(\mathrm{~A})$ and 20 to 70 years, respectively. The other risk factors classified as categorical data and analysed using frequency method. Grade of impairment does not depend solely on area noise but also in combination with age and other risk factors. Characteristic of NIHL prevailed in construction related industries were presented using scatterplots and can serve as a references for future hazard control on site.
\end{abstract}

\section{Introduction}

Noise induced hearing loss (NIHL) is one of the most common occupational disease particularly in construction industries. NIHL remains a problem worldwide despite of step taken to reduce occupational noise exposure by the industries, strict standards for hearing protection and extensive public health awareness campaign [1-6]. In United States, Hong (4) found out that there were significant NIHL problem among operating engineers in construction industries in US. Over $60 \%$ of a total of 623 operating engineers showed hearing loss in the noise-sensitive higher frequencies of 4 and $6 \mathrm{kHz}$. Fig. 1 shows the prevalence of noise-induced hearing loss at selected construction trades at United States from 1996 to 2010 [2]. While in Malaysia, 1047 cases of NIHL have been reported with 499 cases involved in construction related industry from 2012 to 2014 [7].

\footnotetext{
* Corresponding author: zaitonharon@utm.my
} 


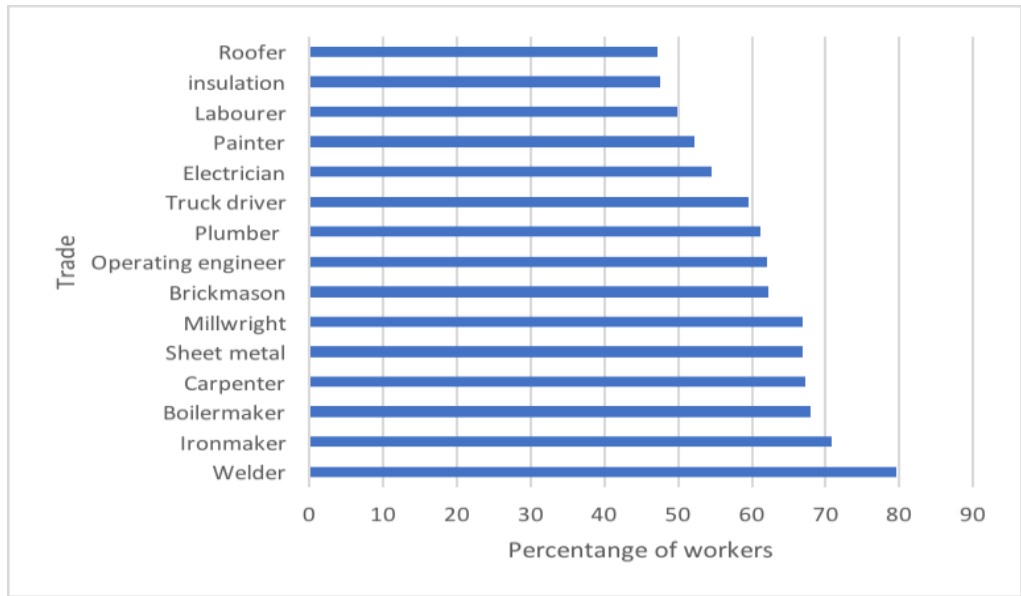

Fig. 1. Prevalence of noise-induced hearing loss at selected construction trades [2].

Noise exposure is an important and highly prevalent occupational hazard in the construction industry. Noise exposures for both ears are converted to binaural hearing impairment percentage [7]. Table 1 shows the grades of hearing impairment and, work performance and recommendation to workers according to binaural hearing impairment percentage. This table was used to obtain the grade of impairment [8]. The grade of impairment criteria are: slight (impairment less than 22.5\%), moderate (impairment range between 22.6 to $52.5 \%$ ), severe (impairment range of 52.6 to $82.5 \%$ ) and profound impairment or deafness (impairment range more than $82.5 \%$ ).

Table 1. Grades of hearing impairment [8].

\begin{tabular}{|c|l|l|l|}
\hline $\begin{array}{c}\text { Hearing } \\
\text { impairment } \\
\text { in \% }\end{array}$ & $\begin{array}{c}\text { Grade of } \\
\text { impairment }\end{array}$ & \multicolumn{1}{|c|}{ Workers Performance } & Recommendations to the workers \\
\hline$<22.5$ & Slight & $\begin{array}{l}\text { Able to hear and repeat words } \\
\text { spoken in normal voice at } 1 \\
\text { metre }\end{array}$ & $\begin{array}{l}\text { Counselling. Hearing aids may be } \\
\text { needed }\end{array}$ \\
\hline $22.6-52.5$ & Moderate & $\begin{array}{l}\text { Able to hear and repeat words } \\
\text { spoken in raised voice at 1 metre }\end{array}$ & $\begin{array}{l}\text { Hearing aids usually } \\
\text { recommended }\end{array}$ \\
\hline $52.6-82.5$ & Severe & $\begin{array}{l}\text { Able to hear some words when } \\
\text { shouted into better ear }\end{array}$ & $\begin{array}{l}\text { Hearing aids needed. If no hearing } \\
\text { aids available, lip-reading and } \\
\text { signing should be taught }\end{array}$ \\
\hline$>82.5$ & $\begin{array}{l}\text { Profound } \\
\text { /deafness }\end{array}$ & $\begin{array}{l}\text { Unable to hear and understand } \\
\text { even a shouted voice }\end{array}$ & $\begin{array}{l}\text { Hearing aids may help } \\
\text { understanding words. Additional } \\
\text { rehabilitation needed. Lip-reading } \\
\text { and sometimes signing essential }\end{array}$ \\
\hline
\end{tabular}

Beside loud noise exposure, there are other attribute that increases the likelihood of developing a known as risk factors. It includes age, cardiovascular disease, diabetes, smoking, chemical exposure, temperature and non-occupational activity or hobby. According to Factory and Machinery Act 1989 [9], a worker must not expose to noise level greater than $90 \mathrm{~dB}(\mathrm{~A})$ for 8 hour in order to avoid the risk of developing hearing loss. 
Moreover, a worker must not expose maximum instantaneous noise level of $135 \mathrm{~dB}(\mathrm{~A})$ and $140 \mathrm{~dB}$. Loud noise produce sound wave that destroys the tiny hair cell in the organ corti within the cochlear of the inner ear, and may cause trauma to ears, which results in chronic effect of hearing loss $[10,11]$. As the workers growing older, the risk of developing hearing loss increase as the inner hair cell deterioration are higher. In addition, if worker have cardiovascular problem the chances of getting hearing loss are more likely due to diminished circulation and narrowing of the blood vessels in the inner ear $[12,13]$. Cardiovascular disease is also associated with cochlear damage [10,14].

Further, diabetic factor show higher prevalence of hearing loss that is associated with a number of microvascular complication which commonly affecting the eyes and the kidneys. These microvascular abnormalities may also affect the ear and hearing ability. Moreover, diabetes and cardiovascular disease have strong correlated relationship and increase the chances of the risk of hearing loss is marginally higher $[15,16]$. In the case of workers with smoking habit, carbon monoxide, a common ingredient in cigarette smoke may cause a temporary threshold shift after long-term exposure by reducing the blood's capacity to deliver oxygen to the cochlea. This cause non-smoker shown lower risk of hearing loss compared to current smoker. Meanwhile ex-smoker presented lower risk of hearing loss compared to non-smoker but ironically passive smoker are facing high risk of hearing loss $[10,12,14]$.

A mixed combination of chemical that have ototoxic properties agent such as toluene, styrene, lead, mercury and noise exposure can act in synergistic way. Chemicals in the bloodstream go through either the blood-labyrinth barrier into the cochlea or the bloodbrain barrier to reach the eighth cranial nerve and the central nervous system. Ototoxic chemicals may affect the structures and/or the function of the inner ear (auditory and vestibular apparatus) and the connected neural pathways [18,19]. Likewise, aromatic solvents most likely affect hearing through chemical poisoning of hair cells, resulting in disorganization of their membranous structures. Higher/lower temperature in workplace can induce heat stress. Combination with high noise exposure and heat stress cause the rate of deterioration of hearing increase rapidly [20].

Any activity that is deemed not occupational or excluded from work scope description also contributed to total noise exposure. A 'buffer time' is required for the hair cells to return to its original positon in order to overcome the noise exposed in work place [21]. The study investigates NIHL among construction industry workers in Malaysia with particular emphasis on its relation with risk factors. The purpose of this study was to (1) determine the prevalence of noise-induced hearing loss among workers in construction industries, and (2) assess the relationship between hearing impairment percentage and risk factors.

\section{Methodology}

A retrospective analysis of record of successful claimants for NIHL compensation from Social Security Organisation (SOCSO) were analysed. These claimants' records were obtained from 2012 to 2014 for various type of job and salary less than RM3000.00. The claimants were 110 workers including machine operators, supervisors, mechanics, technicians, and general worker. Leesen et al. [22] used the same method for determination of exploring the relationship between hearing loss and noise intensity, noise exposure time and the use of hearing protection in the Dutch construction industry. In each record, data obtained were audiometric test for both ears, age, noise level or area noise with its temperature, smoking status, diabetic and cardiovascular status, and hobby. Audiometric test for both ears were then converted to binaural percentage of hearing impairment by using the SOCSO guideline [23]. Grade of impairment were obtained by using Table 1. The 
area noise level and age were classified as non-categorical data and its relationship with hearing impairment were plotted to detect if there were any significant patterns. Others risk factors were categorical data which represented by 'yes' and 'no' and its relatioship with hearing impairment were studied by using frequency analysis method.

\section{Results and discussions}

\subsection{Prevalence of NIHL}

Majority of the claimants came from blue-collar workers; operator (23\%), supervisor (22 $\%)$, mechanic (16\%), technician (11\%), general worker (4\%). They represent $66 \%$ of the total sample population $(\mathrm{N}=110)$ as their nature of work that involved physical work duty and constantly exposed to noise. This result in agreement with previous research that discovered manual labour workers from construction has high risk of hearing loss [2,24]. Fig. 2 shows the distribution of worker with NIHL and its job types. Machine operator had highest percentage and this condition in good agreement with previous research by Haron et al. [24] that $68 \%$ of machine operators were exposed time-weighting average $85 \mathrm{dBA}$ and $18 \%$ of them exceeded the permissible limit of $95 \mathrm{dBA}$. Legris and Pouline [25] also found that the machine or heavy equipment operator had highest noise exposure level.

Meanwhile, Fig. 3 shows the hearing loss obtained from the audiometric test of one of the workers. Analysed by using SOCSO [23] and Table 1, the percentage of hearing impairment and the statistical description of impairment grade is shown in Table 2. It was found that $60.91 \%, 20 \%, 17.27 \%$ and $1.82 \%$ of workers were categorised as slight, medium, severe and medium impairment respectively. The trend shows that the higher the grade of impairment the older the average age of worker but the trend between grade of impairment and average noise area was vice versa.

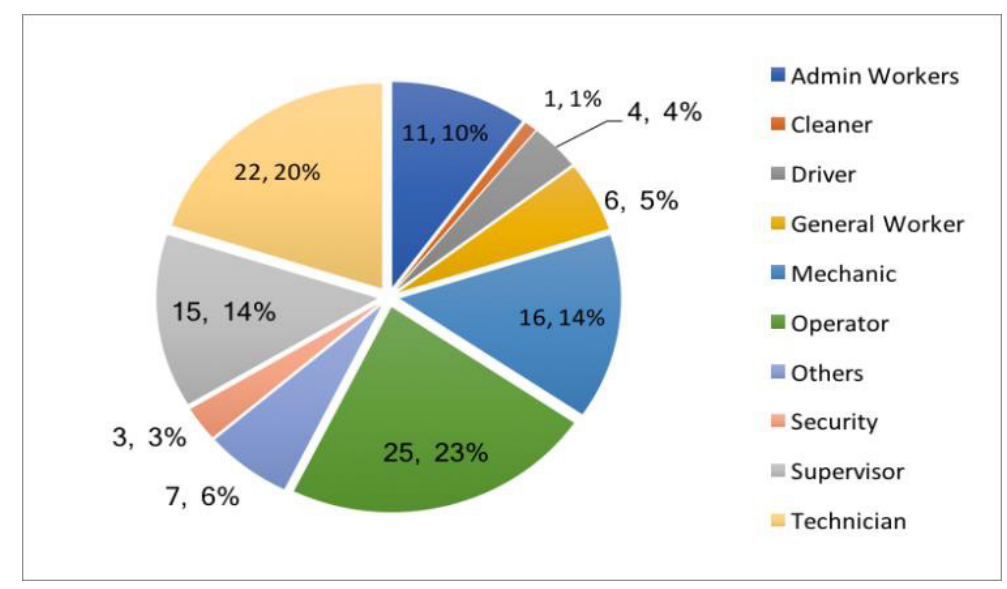

Fig. 2. Distribution of claimant according to type of job. 

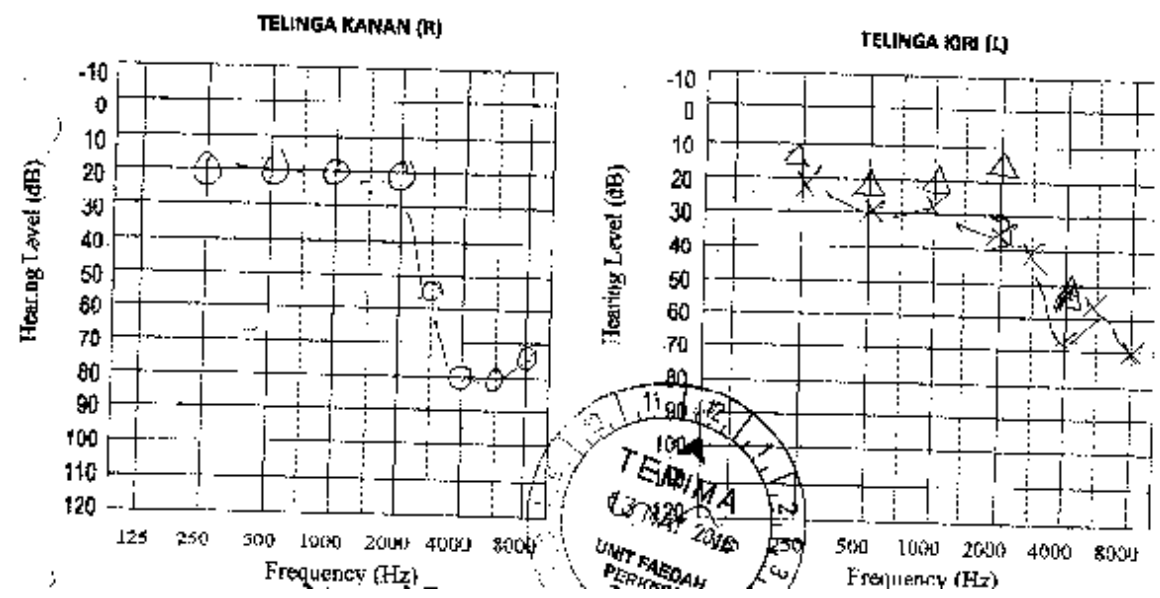

Fig. 3. Audiogram reading for right (R) and left ears (L) used for NIHL compensation claim.

Table 2. Statistical description for non-categorical risk factors.

\begin{tabular}{|c|c|c|c|c|c|}
\hline \multirow{2}{*}{$\begin{array}{c}\text { Impairment } \\
\text { grade }\end{array}$} & \multirow{2}{*}{$\begin{array}{c}\text { Number of } \\
\text { workers } \\
\text { (Percentage) }\end{array}$} & \multicolumn{2}{|c|}{ Area noise, $\mathrm{dB}(\mathrm{A})$} & \multicolumn{2}{|c|}{ Age of workers, years } \\
\cline { 3 - 6 } & Average & Std & Average & Std \\
\hline Slight & $67(60.91)$ & 93.00 & 9.13 & 49.27 & 8.57 \\
\hline Medium & $22(20.00)$ & 92.54 & 9.50 & 53.45 & 6.69 \\
\hline Severe & $19(17.27)$ & 92.06 & 12.08 & 54.11 & 8.31 \\
\hline Profound/deaf & $2(1.82)$ & 89.10 & 2.12 & 59.50 & 7.78 \\
\hline
\end{tabular}

Table 3 shows the percentage of workers with categorical risk factor in each impairment grade group. It is seen that in slight impairment grade there were 12 workers $(17.91 \%)$ exposed to chemical environment, 19 workers $(28.35 \%)$ exposed to high temperature, 13 workers had smoking habit (19.40\%), 8 workers (11.94\%) with diabetic, 4 workers $(5.97 \%)$ with cardiovascular and 9 workers $(13.43 \%)$ with risky/active life style as hobby. The data trend also show that sometimes a worker has more than one categorical factors. As the grade become worsen from medium to profound the number of risky factors appear become less. There were six risk factors for slight, five for medium and severe and none for the profound.

Table 3. Percentage of workers with categorical risk factors.

\begin{tabular}{|c|c|c|c|c|c|c|}
\hline $\begin{array}{c}\text { Impairme } \\
\text { nt grade }\end{array}$ & $\begin{array}{c}\text { Chemical } \\
\text { exposure }\end{array}$ & $\begin{array}{c}\text { High } \\
\text { temperature } \\
\text { exposure }\end{array}$ & $\begin{array}{c}\text { Smoking } \\
\text { habit }\end{array}$ & $\begin{array}{c}\text { Diabetic } \\
\text { disease }\end{array}$ & $\begin{array}{c}\text { Cardiovasc } \\
\text { ular } \\
\text { disease }\end{array}$ & Hobby \\
\hline Slight & $\begin{array}{c}12 \\
(17.91 \%)\end{array}$ & $\begin{array}{c}19 \\
(28.35 \%)\end{array}$ & $\begin{array}{c}13 \\
(19.40 \%)\end{array}$ & $\begin{array}{c}8 \\
(11.94 \%)\end{array}$ & $\begin{array}{c}4 \\
(5.97 \%)\end{array}$ & $\begin{array}{c}9 \\
(13.43 \%)\end{array}$ \\
\hline Medium & 4 & 5 & 3 & 4 & 1 & 0 \\
$(18.18 \%)$ & $(22.72 \%)$ & $(13.63 \%)$ & $(18.18 \%)$ & $(4.5 \%)$ & 0 \\
\hline Severe & 0 & $\begin{array}{c}4 \\
(21.05 \%)\end{array}$ & $\begin{array}{c}4 \\
(21.05 \%)\end{array}$ & $\begin{array}{c}1 \\
(5.26 \%)\end{array}$ & $\begin{array}{c}1 \\
(5.26 \%)\end{array}$ & $\begin{array}{c}1 \\
(5.26 \%)\end{array}$ \\
\hline $\begin{array}{c}\text { Profound/d } \\
\text { eaf }\end{array}$ & 0 & 0 & 0 & 0 & 0 & 0 \\
\hline
\end{tabular}




\subsection{Relationship between NIHL and risk factors}

Fig. 4 shows the plot between hearing impairment and workplace area noise environment. The different zone in $\mathrm{Y}$ axis shows the grade of impairment criteria. Numbers shown in the plot are the ID number(ID\#) for NIHL claimant. In general there were no specific pattern and the range of area noise exposed by the claimant was between 70 to $130 \mathrm{~dB}(\mathrm{~A})$ but majority of the NIHL suferer are exposed in the range of $80 \mathrm{~dB}(\mathrm{~A})$ to $100 \mathrm{~dB}(\mathrm{~A})$ as denoted in circle. However, Figure 5 shows distribution of hearing impairment data according to age. Compared to Figure 4, there were a pattern of relation between percentage of hearing impairment and age of claimant with $12 \%$ of age variation defined the increase of hearing impairment $\left(\mathrm{R}^{2}=0.12\right)$. Data densely distributed around age $50 \mathrm{~s}$ to $60 \mathrm{~s}$. This is consistent with previous study stating that older age is more prone to NIHL [26]. Case ID\# 66 was outlier as he was a young worker that is already partial deaf (on left ear) and not included in regression.

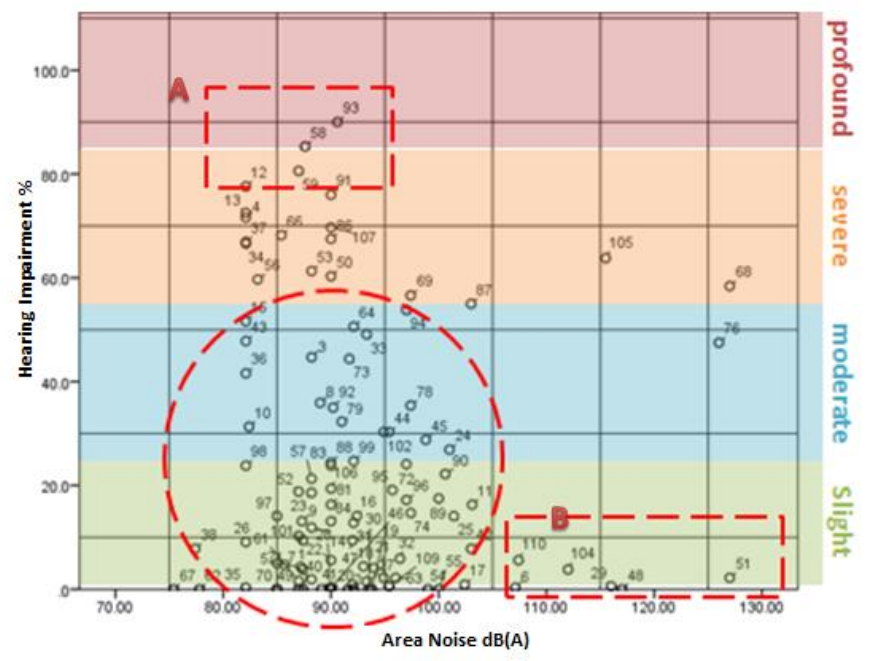

Fig. 4. Characteristic of NIHL: hearing impairment vs area noise.

As explained in Table 2, two sufferers of NIHL (in A zone) were diagnosed as having profound hearing loss who were a supervisor aged 65 (ID\# 58) and a technician aged of 54 (ID\# 93) and both of them has no hobby that can contribute to the extent of hearing loss. On the other hand, worker with ID\# 58 a non-smoker who works for electrical manufacturing exposed to 86 to $93 \mathrm{~dB}(\mathrm{~A})$ in high temperature, has diabetic and ear infection. Combination of risk factors of workplace condition (loud noise exposure, high temperature), age, and diabetic might be the reason for his high grade of hearing impairment and this was in agreement with previous research [10,12,14]. Meanwhile, ID\# 93 worked at factory and exposed only with one risk factor of loud noise environment between $86 \mathrm{~dB}(\mathrm{~A})$ to $93 \mathrm{~dB}(\mathrm{~A})$. The same characteristics were observed by Dawes et al. [12]. There were two reasons that explaining these situations; first, NIHL is influence by age related hearing loss (presbycusis). Second, NIHL is a chronic disease that accumulates with time, continuous exposure manifested more profoundly among workers, as they are expose to noise in longer period of time. Table 4 shows the risk factors for selected claimants in profound and slight impairment grades. 


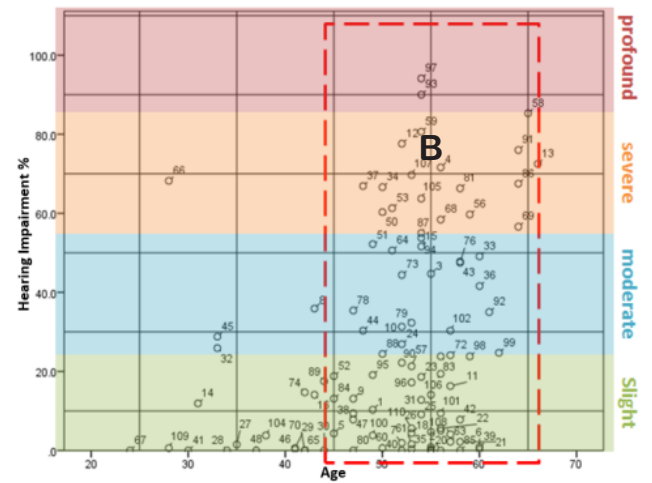

(a) Characteristic of NIHL: Hearing impairment vs age of workers.

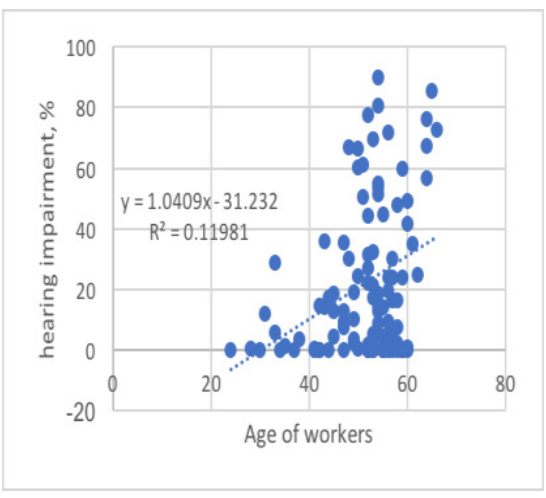

(b) Relation using linear regression.

Fig 5. Hearing impairment versus age.

Study has found 19 of the claimant were fall under the severe grade. The top three on the list were the workers with ID\# 12, 59, and 91 (in A zone). No 12 is a driver in construction related company aged 50, had only exposed to average area of $82.1 \mathrm{~dB}(\mathrm{~A})$. Similarly, worker no. 91 who worked in timber factory exposed only to area noise of 81 $\mathrm{dB}(\mathrm{A})$ without other risk factors is but slightly older of 64 years old. This case shows that while exposed to relatively lower noise, but in combination with age factors can lead to hearing deterioration as stated in [12,13]. While worker ID\# 59 is also exposed to higher area noise $87.0 \mathrm{~dB}(\mathrm{~A})$ and with high temperature and has cardiovascular diseases. This is in agreement with [20] that exposure to heat lead to stress and consequently can lead to cardiovascular disease and compounded the hearing loss induced by loud noise.

Further, for slight impairment category, 6 data cases that are of interest which include the workers with ID\# 6, 28, 48, 51, 104, and 110 (in B zone) albeit were exposed to loud noise exceeded $100 \mathrm{~dB}(\mathrm{~A})$. Workers ID\# 29 (aged 41 years) worked in high temperature and noisy workplace but the slight impairment may be because he was still young. Worker ID\# 48, a 37 years old and has active lifestyle as his hobby while worker ID\# 110 , a 53 years old healthy fit but a smoker. Both of them were in agreement with Kolkhorst et al. [27] that there is moderate association of physical fitness and diminished temporary hearing loss experienced after noise exposure. In addition to that, no 110 have been using hearing protection and this is may be the reason for slight impairment grade he had. This implied that alterations in environmental, lifestyle, or other risks can influence severity of hearing loss regardless of age as suggested by $[12,26]$. Exception was worker ID\# 6 who was surprisingly in this slight impairment category despite of his age of 60 years-old. As suggested by [27] NIHL severity depend much on individual susceptibility and so for worker ID\# 6.

Thus, it was observed from the above that even for the identical area noise, hearing impairment grade can be different. Differences are more noticeable for cases in the range of 80 to $100 \mathrm{~dB}(\mathrm{~A})$. In fact, profound grade are located in the $90 \mathrm{~dB}(\mathrm{~A})$ instead of in high area noise such as at $110 \mathrm{~dB}$ or $140 \mathrm{~dB}(\mathrm{~A})$. This shows the synergistic effect of the combination of the NIHL risk factors [10,28]. Meanwhile, NIHL shows a tendency toward older age despite several younger unconventional cases. Yet, this younger NIHL cases shows the significant effect of risk factors. Most of the high cases show a high influence combination of noise exposure, aging and other risk factors such as active life style or health background (diabetic). The scatterplot results provide simple presentation outlook on the situation occurring on the prevalent of NIHL among construction related industry workers. This 
scatterplot can be use in the future to help providing better awareness on the severity of NIHL risk factors and also law making occupational site regulation.

Table 4. Record of risk factors for selected workers.

\begin{tabular}{|c|c|c|c|c|c|c|c|c|c|}
\hline Grade & 泀 & 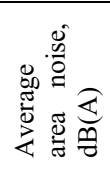 & $\underset{\&}{\infty}$ & 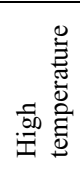 & 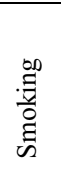 & 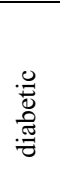 & 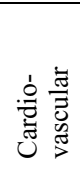 & 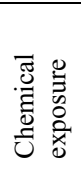 & 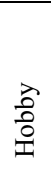 \\
\hline \multirow[t]{2}{*}{ Profound } & 50 & 90 & 65 & Yes & No & Yes & $\mathrm{No}$ & No & No \\
\hline & 93 & 90.6 & 54 & Yes & No & $\mathrm{No}$ & $\mathrm{No}$ & No & No \\
\hline \multirow[t]{3}{*}{ Severe } & 12 & 82.1 & 50 & No & No & No & No & No & No \\
\hline & 59 & 87.0 & 54 & Yes & No & No & Yes & No & No \\
\hline & 91 & 81 & 64 & $\mathrm{No}$ & No & No & No & No & No \\
\hline \multirow[t]{6}{*}{ Slight } & 6 & 107.1 & 60 & Yes & No & No & No & No & No \\
\hline & 29 & 116 & 41 & Yes & No & No & No & No & No \\
\hline & 48 & 117 & 37 & No & No & No & Yes & No & Yes \\
\hline & 51 & 127 & 49 & No & No & No & No & No & No \\
\hline & 104 & 112 & 38 & No & No & No & $\mathrm{No}$ & No & No \\
\hline & 110 & 107.4 & 53 & No & Yes & No & $\mathrm{No}$ & No & Yes \\
\hline
\end{tabular}

\section{Conclusions}

The study was conducted using 110 NIHL record collected from SOCSO. Risk factors such as area noise, age, high temperature, chemical exposure, smoking, hobby, diabetic and cardiovascular are the list that experienced by the claimant of NIHL compensation. There was no direct relationship between area noise with hearing impairment but the range for area noise exposed by claimant were between 70 to $140 \mathrm{~dB}(\mathrm{~A})$ with more data located in the 80 to $100 \mathrm{~dB}(\mathrm{~A})$ zone. Meanwhile, there was low relationship between age and hearing impairment with the age range of claimant was between 20 to 70 years old with denser data between 45 to 65 years old. The profound impairment grade were consist of claimant with area noise of $90 \mathrm{~dB}(\mathrm{~A})$ and age over 50s. There were also case where claimant had similar noise range and age but each case can have different hearing impairment level due to other NIHL risk factors. The scatterplots presented the characteristic of NIHL that prevailed in construction related industries and its can serve as a references for future hazard control on site.

\section{References}

1. M. Sliwinska-Kowalska, D. Adrian, Noise and Health 14, 61 (2012).

2. CPWR,https://www.cpwr.com/sites/default/files/publications/CB\%20page\%2049.pdf (access, 12/1/18)

3. T. Robinson, J. Whittaker, A. Acharya, D. Singh, and M. Smith, Int J Occup Environ Health 21, 1 (2015)

4. O. Hong, Int Arch. of Occup. and Environ. Health 78, 7 (2005)

5. J. Dement, K. Ringen, L. Welch, E. Bingham, P. Quinn, https://dev.btmed.org/PortalDocs/Dement\%20AJIM\%20DOE\%20Hearing\%20\%20M anuscript.pdf

6. N. S. Seixas, B. Goldman, L. Sheppard, R. Neitzel, S. Norton, S. G. Kujawa, Occup Environ Med 62 (2005)

7. $\quad$ SOCSO. Noise Induced Hearing Loss Statistic. Kuala Lumpur (2014)

8. A.N. Mazlan, PhD Thesis, UTM (2017)

9. Factory Machinery Act, (1989) 
10. E. Daniel, Journal of School Health 77, 5 (2007)

11. N.S. Seixas, R. Neitzel, B. Stover, L. Sheppard, P. Feeney, D. Mills, S. Kujawa, Occup and Environ Med, Oemed-2011 (2012).

12. P. Dawes, H. Fortnum, D.R. Moore, R. Emsley, P. Norman, K. Cruickshanks, K. Munro,. Ear Hear 35, 3 (2014)

13. M. Seshamani, M.L. Kashima, Head and Neck Surgery (5th Ed). Philidaphia: PA: Elsevier Mosby (2010)

14. J. Shargorodsky, S.G. Curhan, R. Eavey, G.C. Curhan, the Laryngoscope 120 (2010)

15. O. Hong, J. Buss, E. Thomas, Disease-a-Month 59, 4 (2013)

16. H. Sakuta, , T. Suzuki, H. Yasuda, T. Ito, Diabetes Research and Clinical Practise $\mathbf{7 5}$ (2007)

17. P. Dawes, K.J. Cruickshanks, D.R. Moore, M. Edmondson-jones, A. Mccormack, H. Fortnum, K. Munro, J of the Association for Research in Otolaryngology 15, 4 (2014)

18. T.C. Morata, A.C. Johnson, P. Nylen, E.B. Svensson, J. Cheng, E.F. Krieg, J. Franks, Journal of Occupational and Environmental Medicine 44, 9 (2002)

19. P. Campo, T.C. Morata, O. Hong, Disease-a-Month 59 (2013)

20. C. Chen, Y. Dai, Y. Sun, Y. Lin, Y. Juang, Heat and Workload Exposure (2007)

21. R. Neitzel, N. Seixas, B. Goldman, W. Daniell, The Annals of Occup Hyg 48, 5 (2004)

22. M. C. J. Leensen, J. C. van Duivenbooden, W. A. Dreschler, Int Arch Occup Environ Health 84 (2011)

23. SOCSO, Occup Diseases and Invalidity. 2nd Edition. Kuala Lumpur. (2010)

24. Z. Haron, Z. A. Mardhiah, L. M. Han, K. Yahya, Z Jahya, K. Mohd Said, A. A. Saim, Advanced Materials Research, 838-841 (2014)

25. M. Legris \& P. Poulin, American Industrial Hygiene Association Journal 59, 11 (1998)

26. K. J. Cruickshanks, W. Zhan, W. Zhong, The Aging Auditory System (2010)

27. F.W. Kolkhorst, J.J. Smaldino, S.C. Wolf, L.R. Battani, B.L. Plakke, S. Huddleston, L. Hensley, Medicine and Science in Sports and Exercise 30, 2 (1998)

28. A.L. Edwards, P.Van Coller, C. Badenhorst, Occup Health Southern Africa 16, 4 (2010) 